\title{
Physico chemical properties of irradiated i-SANEX diluents
}

Eros Mossini, Elena Macerata, Marco Giola, Luigi Brambilla, Chiara Castiglioni, Mario Mariani

\begin{abstract}
The development of effective processes to recover minor actinides from spent nuclear fuel cannot leave out of consideration the evaluation of the impact of ionizing radiations on safety, fluid dynamics and extraction efficiency. It is common knowledge from the literature that radiation damage mainly affects the diluents and, indirectly, the extractants [1], but a lack of knowledge remains regarding the radiolytic behavior of innovative selective actinide extraction (i-SANEX) diluents [2,3]. As natural prosecution of the work already performed on diluted nitric acid solutions [4], $0.44 \mathrm{M}$ nitric acid solutions were irradiated in contact with a mixture of kerosene +5 vol. \% 1-octanol by a Co- 60 source at $2.5 \mathrm{kGy} / \mathrm{h}$ dose rate and up to $100 \mathrm{kGy}$ absorbed dose, conditions of interest for the future industrial facility. Density, viscosity, acidity, nitrate anion concentration and phase transfers were systematically measured before and after $\gamma$-irradiation. This was performed because radiation-induced modifications of these parameters may induce alterations of both the fluid dynamics and the separation performances of the extracting system. The results suggest that the fluid-dynamics of the system should be unaltered. In fact, only slight alterations of the organic phase viscosity and of the aqueous phase acidity were measured after irradiation, suggesting the occurrence of limited phase transfers and of diluent by-products formation.
\end{abstract}

Key words: density $\bullet$ i-SANEX $\bullet$ partitioning $\bullet$ radiolysis $\bullet$ Raman $\bullet \mathrm{UV}-\mathrm{Vis} \bullet$ viscosity

E. Mossini ${ }^{\bowtie}$, E. Macerata, M. Giola, M. Mariani Department of Energy,

Politecnico di Milano,

Piazza L. da Vinci 32, Milano, I-20133, Italy,

Tel.: +3902 23996395 ,

E-mail: eros.mossini@polimi.it

L. Brambilla, C. Castiglioni

Department of Chemistry, Materials and Chemical

Engineering "Giulio Natta",

Politecnico di Milano,

Piazza L. da Vinci 32, I-20133 Milano, Italy

Received: 19 June 2015

Accepted: 21 August 2015

\section{Introduction}

Development and public acceptability of nuclear energy cannot disregard safety during both normal operation and fuel waste management. The latter issue could be fulfilled by adopting the closed nuclear fuel cycle to recover the reusable material and to reduce the heat production and the radiotoxicity of the waste [1]. Unlike major actinides, the recovery of minor actinides (MAs) still has to be developed at an industrial scale. One of the possible strategies to be pursued downstream the separation of uranium and/or plutonium consists in the preliminary co-extraction of MAs and lanthanides followed by the selective stripping of the former by means of a hydrophilic complexing agent [5]. The similar chemical behavior of $4 f$ - and $5 f$-elements makes their separation the most difficult step to be accomplished [3]. Several hydrophilic ligands have been studied, but, to date, only few of them seem to be suitable for the industrial process. The most troublesome requirement to be fulfilled for the process feasibility is the radiolytic resistance of the whole system, because diluents and ligands by-products can affect both the separation performances and the fluid dynam- 
ics, leading to alterations of density and viscosity and even to the formation of precipitates and third phases, inducing malfunctioning of mechanic and hydraulic equipment $[6,7]$.

Several studies have been performed to better understand the radiolysis phenomenon concerning the processes devoted to the separation of uranium and/or plutonium $[1,8-10]$ and to the co-extraction of MAs and lanthanides [11-13]. On the other hand, a lack of knowledge remains concerning the MAs stripping step, where the hydrophilic complexing agent is dissolved in diluted nitric acid and it is in contact with the loaded TODGA solution, which is a mixture of kerosene/1-octanol. Preliminary, it is vital to understand the radiolysis effects on the diluents because it is prevalent in the literature that radiation damage mainly affects the diluents and, indirectly, the extractants [1]. With this regard, in the last decades a great deal of effort has been devoted to understand the radiolysis mechanism of nitric acid, in terms of possible by-products identification and of formation yields evaluation [14-17], so as to assess their impact on the actinides chemistry $[7,18$, 19]. Moreover, the composite system concentrated $\mathrm{HNO}_{3}$-organic diluent was studied with particular attention to degradation products impact on PUREX process safety [8-10].

As a logical prosecution of the work already done on diluted nitric acid solutions [4], this paper aims to closely examine the impact of radiation on some physico chemical properties of diluted nitric acid irradiated in contact with kerosene +5 vol.\% 1-octanol, in order to assess the safety and the feasibility of the i-SANEX process based on hydrophilic complexing agent. Some physico chemical properties (such as density, viscosity and acidity) of both aqueous and organic phases were measured before and after irradiation. Fourier transformed (FT)-Raman and UV-Vis spectra were acquired in order to qualitatively ascertain if phase transfers or chemical modifications occurred.

\section{Experimental}

\section{Materials}

All reagents employed in this experimental campaign are analytical grade and were used as received without further purification. Water is Milli-Q gradient from Millipore ${ }^{\circledR}$.

\section{Sample preparation and $\gamma$-irradiation}

20-mL glass vials were filled by equal volume of $0.44 \mathrm{M} \mathrm{HNO}_{3}$ (prepared from Fluka concentrated $\mathrm{HNO}_{3}$ ) and organic diluent (mixture of Sigma-Aldrich kerosene + 5 vol.\% 1-octanol, $\mathrm{K} / \mathrm{O}$ ) up to total volume of $10 \mathrm{~mL}$, in order to leave an adequate empty volume. A Co-60 source characterized by $2.5 \mathrm{kGy} / \mathrm{h}$ dose rate was used for irradiations, that were performed in air up to a total absorbed dose of $100 \mathrm{kGy}$, in agreement with the experimental

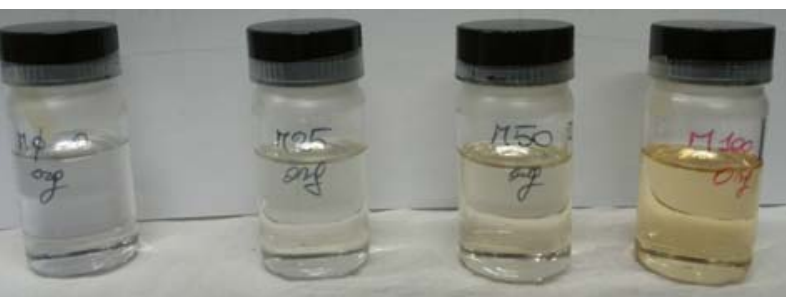

Fig. 1. From the left to the right, mixtures of kerosene + 5 vol.\% 1-octanol irradiated to total absorbed dose of 0 , 25, 50 and $100 \mathrm{kGy}$, respectively, and separated from the aqueous phase.

conditions found in the literature. Samples which were not irradiated, with same ageing and thermal treatment as the irradiated samples, were kept as reference. After irradiation, the samples, previously sealed by a plastic lid to avoid leakages, were kept in the dark at $4^{\circ} \mathrm{C}$. Aqueous and organic phases were physically separated prior to perform the analyses. In Fig. 1 the color change of the organic phases due to irradiation is shown.

\section{Density measurement}

Densities of fresh, aged and irradiated aqueous and organic phases, previously kept for one hour in a thermostatic temperature controlled bath at $20 \pm$ $0.1^{\circ} \mathrm{C}$, were measured by weighing the liquid in a certificated $5 \pm 0.025 \mathrm{~mL}$ flask. Each density value is the mean of three different measurements. The measuring uncertainty takes into account the data standard deviation and the systematic uncertainty associated to the flask volume.

\section{Viscosity measurement}

KPG-UBBELOHDE micro-viscometer with $0.32 \mathrm{~mm}$ diameter capillary was used for the viscosity measurement of fresh, aged and irradiated aqueous and organic solutions. The samples were analyzed at the temperatures of interest for the separation process, between $20^{\circ} \mathrm{C}$ and $45^{\circ} \mathrm{C}$, by means of a thermostatic bath with an error of $\pm 0.1^{\circ} \mathrm{C}$. At each temperature step the equilibration time was set to $10 \mathrm{~min}$ in order to perform the measurements at constant temperature. The analytic procedure is described in a previous paper [4]. The final value of kinematic viscosity comes from the mean of five measurements. The uncertainty has been estimated with the Minimum Mean Square Error method [20] by taking into account the experimental standard deviation, the Hagenback correction and the errors related to temperature variations and the micro-viscometer set-up.

\section{Acidity measurement}

Titration with $0.1 \mathrm{M} \mathrm{NaOH}$ and with methyl orange $0.1 \%$ Fluka solution as end point indicator is used to measure the $\mathrm{H}^{+}$concentration of $0.44 \mathrm{M} \mathrm{HNO}_{3}$ not contacted with the organic phase and of the aqueous phases aged and irradiated in contact. 


\section{Raman analysis}

FT-Raman spectra were recorded by means of a Thermo Electron NXR9650 FT-Raman spectrometer, equipped with a $1064 \mathrm{~nm} \mathrm{Nd:YVO4} \mathrm{laser.} \mathrm{Spectra}$ of liquid samples placed in NMR quartz tubes, were collected in back-scattering geometry using the following parameters: 512 scans, $4 \mathrm{~cm}^{-1}$ resolution, $500 \mathrm{~mW}$ exciting laser power. The analyses were performed at room temperature in the 50 and $3700 \mathrm{~cm}^{-1}$ spectral range.

\section{UV-Vis analysis}

UV-Vis spectra of the pure diluent and of the aqueous phases aged and irradiated in contact were recorded with a dual beam Lambda EZ210 UV/Vis spectrophotometer (PerkinElmer) in the wavelength range of 200-800 nm. Each sample was diluted 1:4 in MilliQ water in order to have a suitable absorbance response.

\section{Results and discussion}

\section{Density}

The measured densities of aqueous and organic samples are reported in Figs. 2 and 3, respectively. Even if the differences between contacted and not-contacted solvents are always within the uncer-

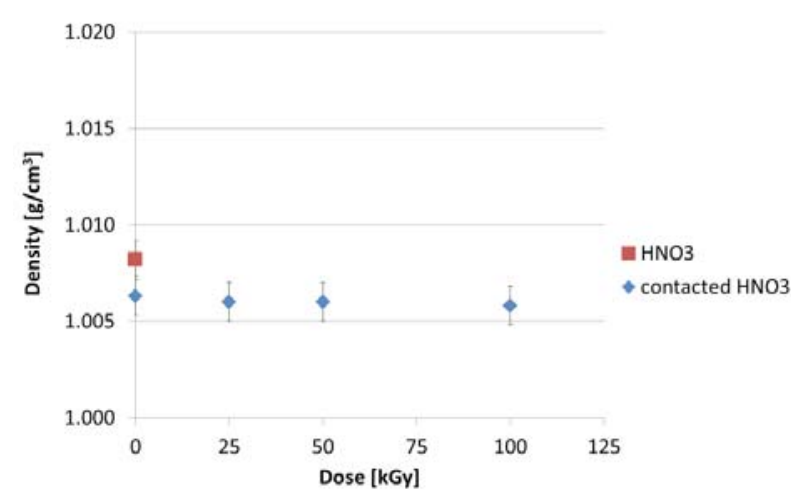

Fig. 2. Density of the aqueous phase as a function of absorbed dose.

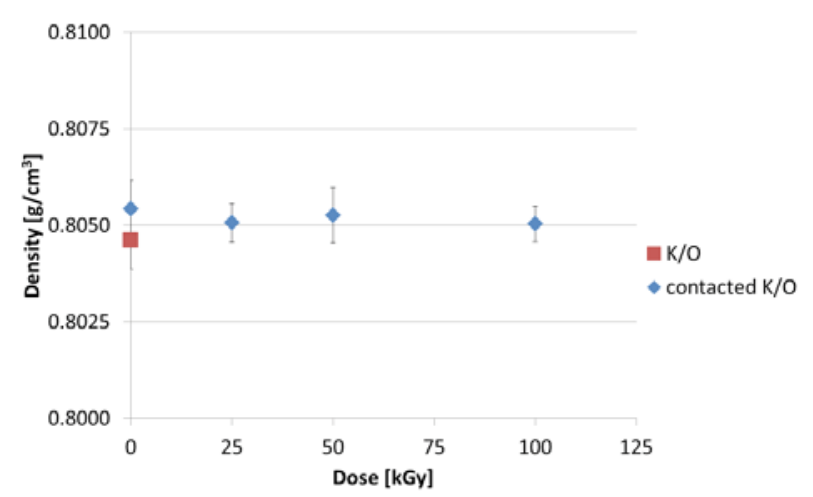

Fig. 3. Density of the organic phase as a function of absorbed dose.

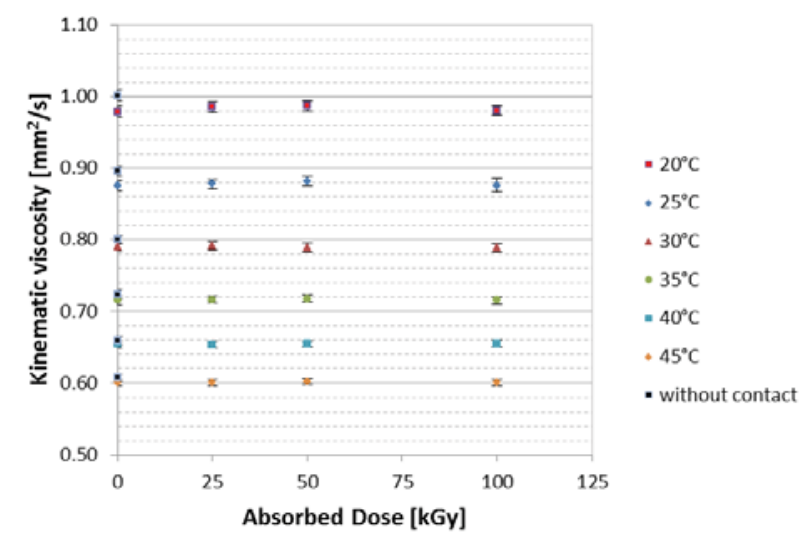

Fig. 4. Kinematic viscosity of the aqueous phase as a function of absorbed dose.

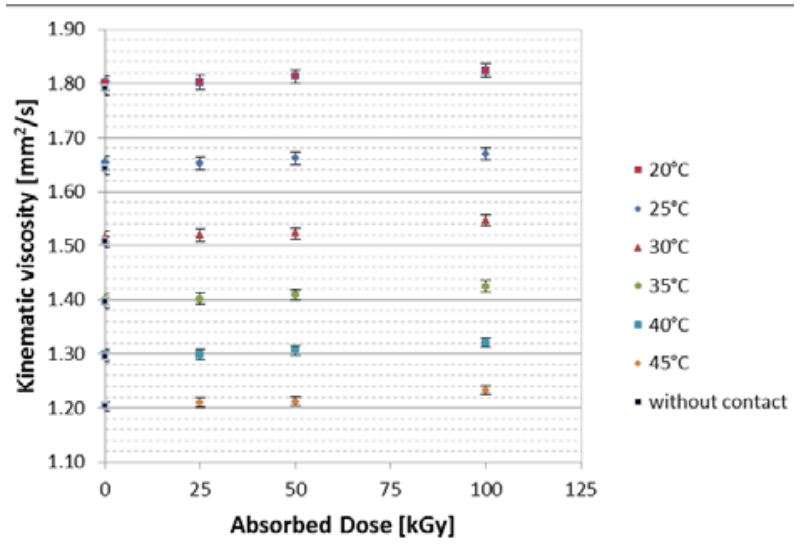

Fig. 5. Kinematic viscosity of the organic phase as a function of absorbed dose.

tainty of the measurements, it could be noted that, after the contact between the two phases, density decreases for the aqueous samples and it increases for the organic ones. This suggests a slight $\mathrm{HNO}_{3}$ extraction in the organic phase due to the contact, in agreement with Ref. [21]. Whereas, no radiation-induced modifications are noticeable within the limit of experimental error.

\section{Viscosity}

The kinematic viscosities of aqueous and organic samples are reported in Figs. 4 and 5, respectively. In both cases, the differences between contacted and not-contacted solvents are within the experimental uncertainty, but a slight viscosity decreases for the aqueous samples and a slight increases for the organic ones could be supposed due to the contact between the two phases, suggesting a slight $\mathrm{HNO}_{3}$ transfer in the organic phase, consistently with the density results and Ref. [21].

While for the aqueous samples no modifications are noticeable in the absorbed dose range considered, for the organic solutions a slight increase of the viscosity is observable. This phenomenon could be ascribed to a partial by-products trapping in the organic phase. 


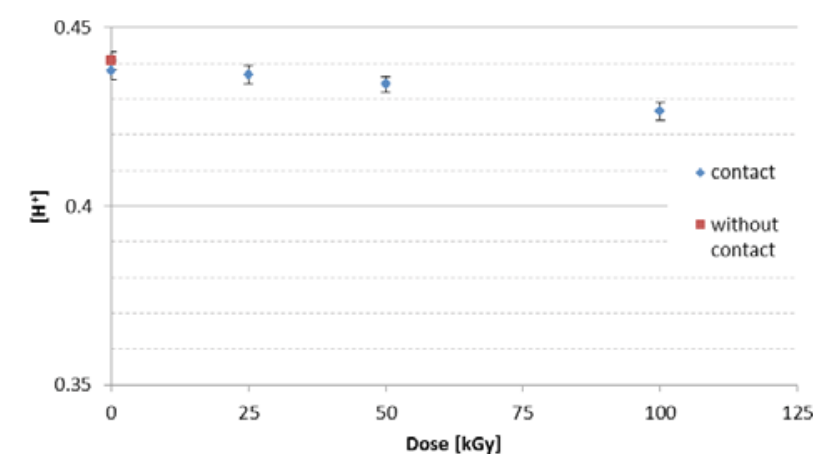

Fig. 6. $\left[\mathrm{H}^{+}\right]$in the aqueous phase as a function of absorbed dose.

\section{Acidity}

The results are reported in Fig. 6. The uncertainty related to the measure is between $0.5 \%$ and $0.6 \%$. The difference due to the contact between the two phases is negligible (but in agreement with the abovementioned results) and within the limit of the experimental error, while a decrease of $\left[\mathrm{H}^{+}\right]$is noticeable with increasing absorbed dose, leading to $\left[\mathrm{H}^{+}\right]$reduction of about $3 \%$ at $100 \mathrm{kGy}$. In the previous work, no radiation-induced modification was found for nitric acid irradiated alone, further proof of the interaction between by-products of the two diluents [4].

\section{Spectroscopic study}

FT-Raman spectroscopic and UV-Vis spectrophotometric techniques were exploited in order to better understand the results of the physico chemical experiments, in particular with the aim of shining a light on phase transfers and on radiation-induced alterations of nitrate ion concentration. In fact, this anion reacts with water by-products leading to the formation of nitrous anion [16, 17], which plays a critical role in the redox chemistry of actinides, and thus on the efficiency of the separation process $[12,22]$. Since nitrous anion immediately decomposes in acidic solutions, nitrate ion concentration was monitored [16].

\section{FT-Raman spectroscopy}

The spectra of aqueous and organic samples are reported in Figs. 7 and 8. A quantitative analysis is not possible due to the absence of a reference signal. In the aqueous samples spectra, the nitrate anion peak is visible at $1047 \mathrm{~cm}^{-1}$ while, water $\mathrm{OH}$ stretching and $\mathrm{HOH}$ bending signals are week and the nitrite anion peak is not distinguishable from the background noise [23]. Concerning the organic samples, the main characteristic functional groups of kerosene and 1-octanol are visible in the spectra. In both cases, no differences could be seen between the spectra of the pure diluent (spectrum on the top of Figs. 7 and 8 ) and the spectra of the contacted and irradiated solutions. The FT-Raman technique does not seem to be sensible enough to reveal any radiation-induced alterations since no appreciable modification between

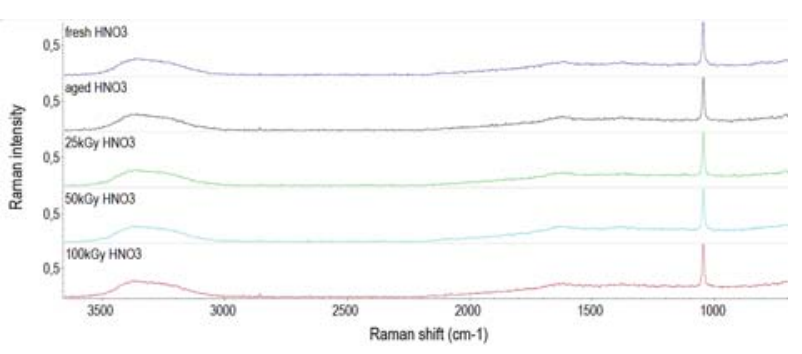

Fig. 7. FT-Raman spectra of aqueous samples, from the top to the bottom: fresh $0.44 \mathrm{M} \mathrm{HNO}_{3}$, and the separated aqueous phases after irradiation to $0,25,50,100 \mathrm{kGy}$, respectively.

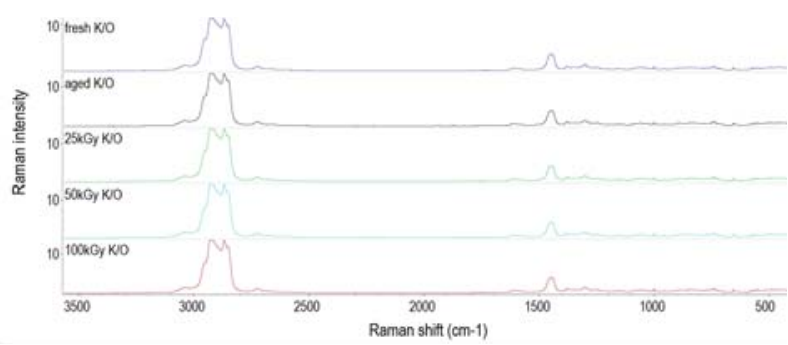

Fig. 8. FT-Raman spectra of organic samples, from the top to the bottom: fresh kerosene +5 vol.\% 1-octanol, physically separated organic phases after irradiation to 0 , 25, 50, $100 \mathrm{kGy}$, respectively.

the spectra of the contacted solutions is noticeable. Therefore, it seems to be reasonable to exploit FT-IR spectroscopy for organic by-products analysis.

\section{UV-Vis spectrophotometry}

The spectra of aqueous phases are reported in Fig. 9. Each spectra was acquired with water as reference.

The nitrate anion peak is visible at about $301 \mathrm{~nm}$, but the evaluation of its concentration change due to irradiation is not possible because new contributions appear in the irradiated samples at about 250-280 $\mathrm{nm}$ and at 330-380 $\mathrm{nm}$. These were probably engendered by 1-octanol hydrophilic by-products and by nitric acid by products, e.g. $\mathrm{HNO}_{2}$ and $\mathrm{NO}_{2}$. As preliminary confirmation of this hypothesis, alcohols and nitrous compounds are known to have UV-Vis absorption peaks in the first and in the second wavelength range respectively [24]. In the previous work a slight decrease in the concentration of nitrate anion was found, but no new peaks ap-

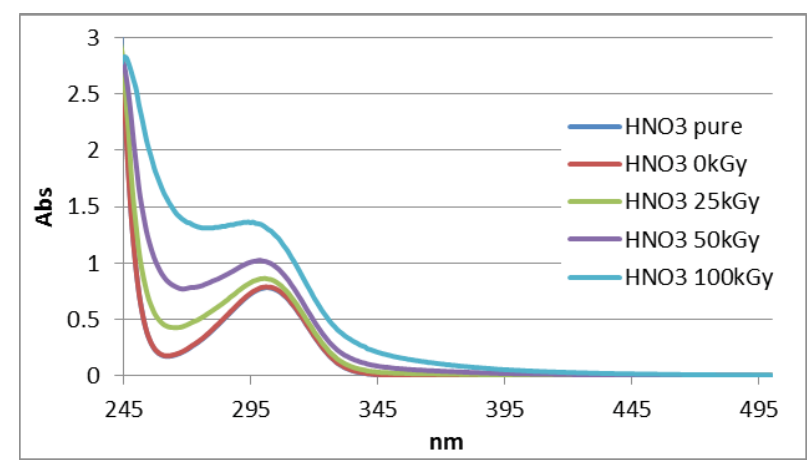

Fig. 9. UV-Vis spectra of aqueous samples diluted 1:4 with MilliQ water. 
peared, probably because of the by-products volatile nature [4]. On the contrary, in this case the organic phase acts as a barrier for the by-products migration.

\section{Conclusions}

As natural prosecution of the previous work, in this paper the effects of radiation on some physico chemical properties of the diluents to be used in innovative advanced processes for the MAs partitioning is presented in order to obviate the literature dearth [4]. In fact, the radiolytic behavior of the PUREX diluents was deeply studied in the past decades, but still a lack of knowledge exists concerning the radiolytic behavior of diluted nitric acid and organic diluents.

A slight increase of the organic phase viscosity and a slight decrease of the aqueous phase acidity were measured after irradiation, suggesting the occurrence of limited phase transfers and of diluents by-products formation, therefore the fluid-dynamics of the system should be unaltered. To shine a light on these hypotheses, FT-Raman and UV-Vis spectra were acquired. In particular, by means of spectrophotometric analysis of the aqueous samples it was possible to find radiation-induced differences, this could be in agreement with the production of hydrophilic by-products of the diluents.

Further investigations are already in progress by gas chromatography-mass spectrometry (GC-MS) and FT-IR in order to explicate the slight modifications of some physico chemical properties and to evaluate the impact of radiation on the system. To conclude, the experimental campaign, the organic phase containing the lipophilic extractant and the aqueous phase with the hydrophilic complexing agent should be studied after irradiation in contact, possibly in continuous mixing.

Acknowledgment. The authors wish to thank Gammatom Srl for the irradiation campaign. This work was partially funded by the SACSESS European Commission Project (FP7-CP-2013-323282).

\section{References}

1. Mincher, B. J., Modolo, G., \& Mezyk, S. P. (2009). The effects of radiation chemistry on solvent extraction: 1. Conditions in acidic solution and a review of TBP radiolysis. Solvent Extr. Ion Exch., 27, 1-25. DOI: 10.1080/07366290802544767.

2. Tripathi, S. C., \& Ramanujam, A. (2003). Effect of radiation-induced physicochemical transformations on density and viscosity of 30\% TBP-n-dodecane- $\mathrm{HNO}_{3}$ system. Separ. Sci. Technol., 38, 2307-2326. DOI: $10.1081 / \mathrm{SS}-120021626$.

3. Bourg, S., Poinssot, C., Geist, A., Cassayre, L., Rhodes, C., \& Ekberg, C. (2012). Advanced reprocessing developments in Europe status on European projects ACSEPT and ACTINET-I3. Procedia Chem., 7, 166-171. DOI: 10.1016/j.proche.2012.10.028.

4. Mossini, E., Macerata, E., Giola, M., Brambilla, L., Castiglioni, C., \& Mariani, M. (2015). Radiation- -induced modifications on physico chemical properties of diluted nitric acid solutions within advanced spent nuclear fuel reprocessing. J. Radioanal. Nucl. Chem., 304, 395-400. DOI: 10.1007/s10967-0143556-5.

5. Bourg, S., Hill, C., Caravaca, C., Rhodes, C., Ekberg, C., Taylor, R., Geist, A., Modolo, G., Cassayre, L., Malmbeck, R., Harrison, M., de Angelis, G., Espartero, A., Bouvet, S., \& Ouvrier, N. (2009). ACSEPT-Partitioning technologies and actinide science: towards pilot facilities in Europe. $\mathrm{Nucl}$. Eng. Des., 241, 3425-3427. DOI: 10.1016/j.nucengdes.2011.03.011.1.

6. Mincher, B. J., Modolo, G., \& Mezyk, S. P. (2010). The effects of radiation chemistry on solvent extraction 4: separation of the trivalent actinides and considerations for radiation-resistant solvent system. Solvent Extr. Ion Exch., 28, 415-436. DOI: 10.1080/07366299.2010.485548.

7. Pikaev, A. K., Kabakchi, S. A., \& Egorov, G. F. (1988). Some radiation chemical aspects of nuclear engineering. Radiat. Phys. Chem., 31, 789-803. DOI: 10.1016/1359-0197(88)90260-3.

8. Tripathi, S. C., Bindu, P., \& Ramanujam, A. (2001). Studies on the identification of harmful radiolytic products of 30\% TBP-n-dodecane- $\mathrm{HNO}_{3}$ by gas liquid chromatography. I. Formation of diluent degradation products and their role in $\mathrm{Pu}$ retention behavior. Separ. Sci. Technol., 36, 1463-1478. DOI: 10.1081/ SS-100103882.

9. Krishnamurthy, M. V., \& Sampathkumar, R. (1992). Radiation-induced decomposition of the tributyl phosphate-nitric acid system: role of nitric acid. J. Radioanal. Nucl. Chem., 166, 421-429. DOI: 10.1007/ BF02167787.

10. Tripathi, S. C., \& Ramanujam, A. (2003). Effect of radiation induced physicochemical transformation on density and viscosity of 30\% TBP-n-dodecane- $\mathrm{HNO}_{3}$ systems. Separ. Sci. Technol., 38, 2307-2326. DOI: 10.1081/SS-120021626.

11. Sugo, Y., Sasaki, Y., \& Tachimori, S. (2002). Studies on hydrolysis and radiolysis of $\mathrm{N}, \mathrm{N}, \mathrm{N}^{\prime}, \mathrm{N}^{\prime}$-tetraoctyl3-oxapentane-1,5-diamide. Radiochim. Acta, 90, 161-165. DOI: 10.1524/ract.2002.90.3 2002.161.

12. Sugo, Y., Izumi, Y., Yoshida, Y., Nishijima, S., Sasaki, Y., Kimura, T., Sekine, T., \& Kudo, H. (2007). Influence of diluent on radiolysis of amides in organic solution. Radiat. Phys. Chem., 76, 794-800. DOI: 10.1016/j.radphyschem.2006.05.008.

13. Ansari, S. A., Pathak, P., Mohapatra, P. K., \& Manchanda, V. K. (2012). Chemistry of diglycolamides: promising extractants for actinide partitioning. Chem. Rev., 112, 1751-1772. DOI: 10.1021/cr200002f.

14. Katsumura, Y., Jiang, P. Y., Nagaishi, R., Yotsuyanagi, T., \& Ishigure, K. (1994). $\gamma$-Radiolysis study of concentrated nitric acid solutions. J. Chem. Soc. Faraday Trans., 90, 93-95. DOI: 10.1039/FT9949000093.

15. Savel'ev, Y. I., Ershova, Z. V., \& Vladimirova, M. V. (1967). $\alpha$-Radiolysis of aqueous solutions of nitric acid. Sov. Radiochem., 9, 221-225.

16. Kazanjian, A. R., Miner, F. J., Brown, A. K., Hagan P. G., \& Berry, J. W. (1970). Radiolysis of nitric acid solutions: L.E.T. effects. Trans. Faraday Soc., 66, 2192-2198. DOI: 10.1039/TF9706602192.

17. Katsumura, Y., Jiang, P. Y., Nagaishi, R., Oishi, T., Ishigure, K., \& Yoshida, Y. (1991). Pulse radiolysis study of aqueous nitric acid solutions. Formation mechanism, yield, and reactivity of $\mathrm{NO}_{3}$ radical. J. Phys. Chem., 95, 4435-4439. DOI: 10.1021/ j100164a050. 
18. Bhattacharyya, P. K., \& Natarajan, P. R. (1991). Radiation chemistry of actinide solutions. In A. J. Freeman, \& C. Keller (Eds.), Handbook on the physics chemistry of the actinides (Chapter 13). Amsterdam: Elsevier.

19. Nagaishi, R. (2001). A model for radiolysis of nitric acid and its application to the radiation chemistry of uranium ion in nitric acid medium. Radiat. Phys. Chem., 60, 369-375. DOI: 10.1016/S0969$806 \mathrm{X}(00) 00410-2$.

20. Taylor, J. R. (1996). An introduction to error analysis: The study of uncertainties in physical measurements. 2nd ed. Sausalito: Univ. Science Books.

21. Geist, A. (2010). Extraction of nitric acid into alcohol: Kerosene mixtures. Solvent Extr. Ion Exch., 28, 596-607. DOI: 10.1080/07366299.2010.499286.
22. Nash, K. L., \& Lumetta, G. J. (2011). Advanced separation techniques for nuclear fuel reprocessing and radioactive waste treatment. Cambridge: Woodhead Publishing Limited.

23. Aksenenko, V. M., Murav'ev, N. S., \& Taranenko, G. S. (1986). Raman scattering study of nitric acid solutions. J. Appl. Spectrosc., 44, 87-91. DOI: 10.1007/ BF00658324.

24. Maddigapu, P. R., Minero, C., Maurino, V., Vione, D., Brigante, M., Charbouillot, T., Sarakha, M., \& Mailhot, G. (2011). Photochemical and photosensitised reactions involving 1-nitronaphthalene and nitrite in aqueous solution. Photochem. Photobiol. Sci., 10, 601-609. DOI: 10.1039/c0pp00311e. 